\title{
A limitation of the contrafreeloading phenomenon*
}

\section{GEORGE T. TAYLOR $†$ \\ State University of New York, College at Potsdam, Potsdam, N.Y. 13676}

Two experiments were performed in an attempt to replicate first and then to generalize a contrafreeloading effect, i.e., that animals would rather work and get rewards than get the rewards free. The first experiment failed to replicate the earlier experiments with hungry animals and food as reinforcement, as only 3 of the 25 rats exhibited a preference for barpressing. The remaining animals demonstrated a prefere ice for the free food that increased over free choice days. The second experiment attempted to generalize these findings, using thirsty animals and water as the reward. The data were consistent with the food results; however, the preference for free water was even greater than that for free food. The results were viewed as suggesting that the speculations that animals prefer working to freeloading were premature.

There has recently been a revival of interest (e.g., Carder \& Berkowitz, 1970; Neuringer, 1969,1970 ) in a contrafreeloading phenomenon initially suggested in a study by Jensen (1963). He had found that, given a choice between free food and a previously established operant response for the food, rats will continue to respond and eat in the presence of free food. Unfortunately, Jensen chose to interpret his data as suggesting that rats prefer barpressing to freeloading, although his data demonstrates that only with extended initial barpress training (over 640 responses) did the animals actually prefer, i.e., over $50 \%$, the earned food. Subsequent investigators have implied that animals invariably prefer to work for food rather than get the food freely (e.g., Carder \& Berkowitz, 1970; Singh, 1972). Therefore, the contrafreeloading "phenomenon" appears to suggest two conclusions, which may or may not be mutually exclusive. The iirst is that animals will barpress for food when free food is available. A second conclusion with somewhat wider implications is that animals prefer to work for food rather than freeload.

The notion that animals "enjoy" working and actually prefer (greater liking) to work rather than freeload is not only contrary to intuition, but also to a large body of findings in animal learning. It is difficult to reconciliate these data with such well-established results as the rat's preference for the shorter, less effortful path to a goal (Logan, 1960;

* The research was supported in part by NSF Grant GB-12954 to Dr. Frank A. Logan.

These data were generated in two different laboratories, Dr. Logan's lab at the University of New Mexico and the Psychological Lab at the State University of New York, College at Potsdam.
Tolman, 1955; Yoshioka, 1929) and also with the findings relating the preference, provided density of reinforcement is relatively equal, of pigeons for the shorter of two reinforcement schedules (cf. Reynolds, 1968) and even the extinction of an operant response following removal of the reinforcement (cf. Skinner, 1938). Considering the rather contradictory evidence generated in the freeloading context, the first of the present experiments represents an attempt to replicate those preference data with food as reinforcement. The second experiment is an attempt to examine the generality of this freeloading conclusion to a setting involving a different reinforcer, namely, water.

\section{EXPERIMENT I} Subjects

The Ss were 10 male and 15 female albino rats of the Sprague-Dawley strain obtained from a commercial supplier. The experimentally naive animals, approximately 100 days old at the beginning of experimentation, were housed in individual cages with water freely available.

\section{Apparatus}

The experimental chambers consisted of eight identical operant boxes, $81 / 2 \times 9 \times 8 \frac{1}{2}$ in. The chambers each had a recessed food magazine in the center of the end wall and a bar to the left of the magazine. The two end walls were aluminum and the side walls and top were clear Plexiglas. The floor of the chamber was composed of 3/16-in. stainless steel rods spaced $3 / 4$ in. apart. The boxes were housed in a series of recessed cabinets. Finally, the free food was introduced in a small glass dish, $3 \frac{1}{2}$ in. in diam and $1 / 2$ in. deep.

Pretraining. All Ss were gentled and adapted to a 23-h food-deprivation schedule for 7 days prior to the beginning of experimentation. On the first day of pretraining, the animals were shaped to barpress for $45-\mathrm{mg}$ Noyes pellets on CRF. The animals were allowed to press $20 \mathrm{~min}$ per day until a total of 1,000 pellets were earned. After each experimental session, the animals were returned to their home cages and fed $12 \mathrm{~g}$ of laboratory chow minus the amount eaten in the experimental chamber. On the day following completion of the 1,000 barpresses, a small glass dish containing 300 pellets was introduced for 1 day and, with the bar covered, the animal was allowed to eat from the dish. The following day free choice testing began.

Free choice testing. The free food dish was filled with 300 pellets and placed at the opposite end of the box to the bar and magazine. The animals were placed into the apparatus and given a choice between eating the free food or working on the CRF schedule for the pellets. The animals were given a total of 15 experimental sessions, 20 min per day. Each day the total number of pellets eaten from the free dish and earned from the barpress were counted and a percentage of pellets obtained from the free dish was calculated.

\section{Results}

Figure 1 notes the mean percentage of pellets eaten by the animals during the experimental sessions. The data demonstrate a mild preference, i.e., over $50 \%$, for free food on Day $1\left(x^{2}\right.$ $=3.36, \mathrm{df}=1, \mathrm{p}<.10$ ). Subsequently, there is a progressive increase in this preference so that by the end of the experiment, the animals as a group consistently prefer the free food $\left(x^{2}=\right.$ 8.92 , df $=1, p<.01$ ). Only 3 of the 25 animals, 2 males and 1 female, exhibited an actual preference for the earned food. Finally, informal observations suggested that, except for those 3 Ss, the probability of a barpress greatly increased with the passage of time in each experimental session. However, the 3 "workers" began pressing almost immediately upon being placed into the apparatus.

\section{EXPERIMENT II \\ Subjects}

The Ss in the second experiment were 25 male albino rats of the Sprague-Dawley strain obtained from a commercial supplier. The experimentally naive animals, 90-120 days old at the beginning of experimentation, were housed individually with food freely available. Apparatus

The experimental chambers were 10 identical operant boxes, $81 / 2 \times 9 \times$ $8 \frac{1}{2}$ in. The chambers each had a water delivery system consisting of a hole, 2 in. in diam, in the end panel through which the animal could reach a water dipper which, when filled, held exactly 


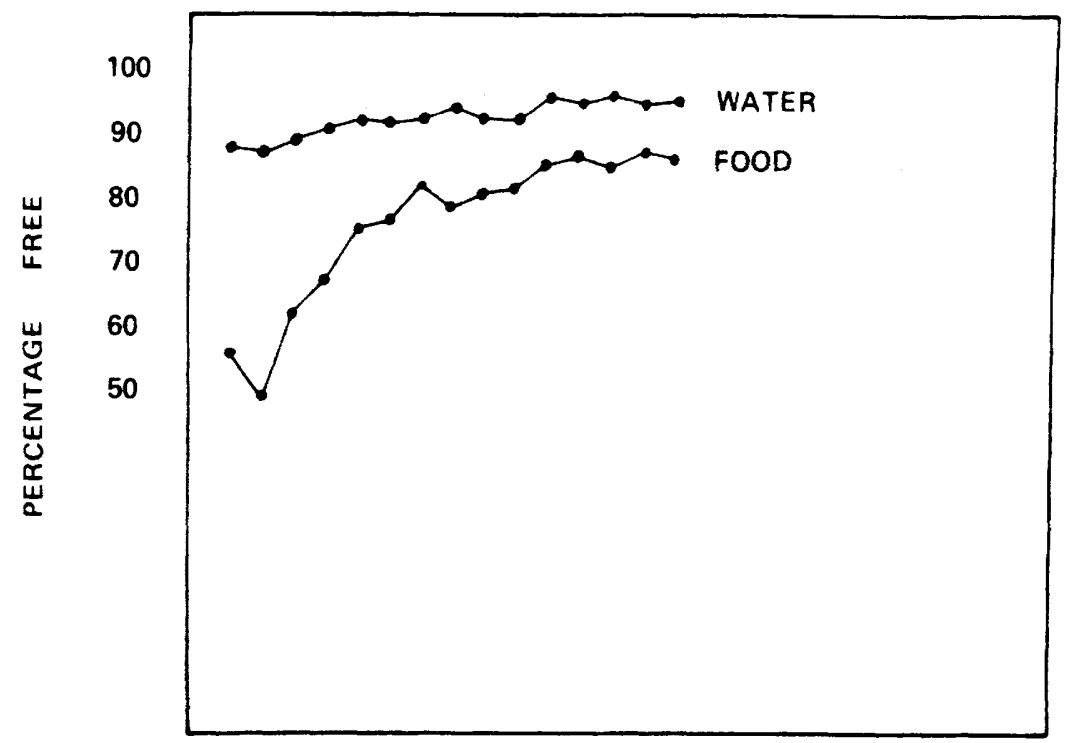

123456789101112131415

\section{DAY}

Fig. 1. The percentage of total intake under freeloading condition of animals in a food and in a water setting for 20 min each day.

$.01 \mathrm{ml}$ of water. The two end walls of the apparatus were aluminum and the side walls and top were clear Plexiglas. The floor of the chamber consisted of 3/16-in. stainless steel rods spaced $1 / 2$ in. apart. Free water was introduced in a small plastic dish, 3 in. deep and with a $2 \frac{1}{2}$-in. diam.

\section{Procedure}

The procedure in the water setting was closely akin to the procedure in Experiment I. Animals were gentled and ad a p ted to a $23-\mathrm{h}$ water-deprivation schedule and allowed to press on CRF for water. The animals were allowed to press in sessions of $20 \mathrm{~min} / \mathrm{day}$ until completion of 1,000 responses. After each experimental session, the animals were given $25 \mathrm{ml}$ of water, minus the amount consumed in the apparatus, from the home water bottles. The day following completion of the 1,000 responses, the bar was covered and $20 \mathrm{ml}$ of free water introduced into the opposite corner to the bar and magazine. The following day the animals were given a free choice to drink free or press a bar for water.

\section{Results}

The data overwhelmingly support the notion that the animals prefer free water rather than working for it (Fig. 1). These observations were also supported statistically for Day $1\left(x^{2}=\right.$ 10.02 , $\mathrm{df}=1, \mathrm{p}<.01$ ) and for the entire experiment $\left(x^{2}=14.12, \mathrm{df}=1\right.$, $\mathrm{p}<.001)$. Furthermore, a high preference for free water was prevalent from the first day, increasing progressively over days and terminating at around $95 \%$. Finally, none of the animals preferred to work for water. These data give no support whatsoever to the generality of the conclusion that animals prefer to work rather than freeload.

\section{DISCUSSION}

The data from the two experiments represent a failure both to replicate the previous findings (e.g., Carder \& Berkowitz, 1970) that rats prefer earned to free food and to extend the preference findings to another reinforcement setting, i.e., water. As a result, it appears that the earlier speculations (Singh, 1972) that animals prefer to work for rewards rather than get them free were experiments reporting this contrafreeloading conclusion, only Jensen (1963) ran a substantial number of animals-some 200 rats of various ages. However, he only allowed the animals one free choice day, i.e., to choose between barpressing for premature. Of the previous food and free food. The resulting data, taken as a whole, were not dramatically different from the present findings in the food setting on Day 1 . One could then speculate that Jensen would have generated comparable data to the present findings if the animals had been given extended free choice training. Furthermore, the results of the second experiment suggest that when other rewards are employed, there is an even greater reduction in the probability of a barpress response in the presence of the reward presented freely.

In sum, granting that 3 of the 25 animals in the food setting did prefer to work, the data of the remaining animals and the conclusiveness of the findings in the water setting suggest that, if the preference conclusion of the contrafreeloading phenomenon is sometimes proper, it is a principle that lacks generality. The author's confidence with this statement is somewhat enhanced by the fact that these data were generated in different experimental environments in two quite different laboratories.

However, the other conclusion implied by the Jensen (1963) study, i.e., that animals will in fact barpress in the presence of free rewards, appears confirmed. Thus, the data of the two investigations suggest a limitation of the contrafreeloading phenomenon to implicate only that conclusion.

\section{REFERENCES}

CARDER，B \& BERKOWITZ, $K$, Rats preference for earned in comparison with free food. Science, $1970,167,1273$

JENSEN, G. D. Preference for bar pressing over "freeloading" as a function of number of rewarded presses. Journal of Experimental Psychology, 1963, 65, $451-454$.

LOGAN, $\mathrm{F}$. A. Incentive. New Haven, Conn: Yale University Press, 1960.

NEURINGER, A. J. Animals respond for food in the presence of free food. Science, 1970, 166, 399-401.

NEURINGER, A. J. Many responses per food reward with free food present. Science, 1970, 168, 503-504.

REYNOLDS, G. S, A primer of operant conditioning. Glenview, Ill: Scott Foresman, 1968.

SINGH, D. The pied piper vs the protestant ethic. Psychology Today, 1972, 5, 53-56.

SKINNER, B. F. The behavior of organisms. New York: Appleton-Century-Crofts, 1938.

TOLMAN, E. C. Principles of performance. Psychological Review, 1955, 62, 315-326.

YOSHIOKA, J. G. Weber's law in the discrimination of maze distance by the $w$ hite rat. University of California Publication of Psychology, 1929, 4, 155-184. 